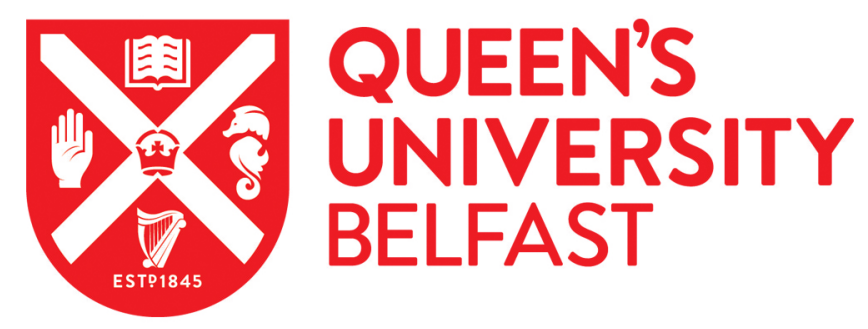

\title{
A cluster randomised controlled trial and process evaluation of the early years DELTA parenting programme
}

Miller, S., \& Harrison, H. (2015). A cluster randomised controlled trial and process evaluation of the early years DELTA parenting programme. International Journal of Educational Research, 74, 49-60.

https://doi.org/10.1016/j.ijer.2015.09.006

Published in:

International Journal of Educational Research

Document Version:

Peer reviewed version

Queen's University Belfast - Research Portal:

Link to publication record in Queen's University Belfast Research Portal

Publisher rights

(c) 2015, Elsevier. Licensed under the Creative Commons Attribution-NonCommercial-NoDerivatives 4.0 International

$\mathrm{http}: / /$ creativecommons.org/licenses/by-nc-nd/4.0/which permits distribution and reproduction for non-commercial purposes, provided the author and source are cited.

\section{General rights}

Copyright for the publications made accessible via the Queen's University Belfast Research Portal is retained by the author(s) and / or other copyright owners and it is a condition of accessing these publications that users recognise and abide by the legal requirements associated with these rights.

Take down policy

The Research Portal is Queen's institutional repository that provides access to Queen's research output. Every effort has been made to ensure that content in the Research Portal does not infringe any person's rights, or applicable UK laws. If you discover content in the Research Portal that you believe breaches copyright or violates any law, please contact openaccess@qub.ac.uk. 
Title: A cluster randomised controlled trial evaluation of the early years DELTA parenting programme Authors: Sarah Miller, Helen Harrison

Affiliation: (Centre for Effective Education), Queen's University Belfast, Northern Ireland

Corresponding author: Sarah Miller, Centre for Effective Education, School of Education, Queen's University Belfast, 69-71 University Street, Belfast, BT7 1HL, Northern Ireland.

Email: s.j.miller@qub.ac.uk 


\begin{abstract}
This paper reports the results from a cluster randomised controlled trial (RCT) and process evaluation of the Early Years DELTA Parenting Programme; a six-week, group based intervention. The evaluation was part funded by DELTA and involved 23 primary schools and 334 parents. Results showed that intervention parents reported increased parental self-efficacy in relation to: knowledge of their child's development and needs; self-acceptance as a good parent, and; disciplining and setting boundaries. No change was observed in the remaining outcome areas. Parent interviews indicated a high level of programme satisfaction and the main benefits reflected the outcomes measured by the RCT. This small, robust evaluation is commensurate with other similar research demonstrating the effectiveness and reach of short-term, group-based parenting programmes.
\end{abstract}

\title{
Highlights
}

- This RCT evaluated the impact of a group parenting programme on parent outcomes

- It was effective in improving some (but not all) domains of parental self-efficacy

- There was no effect of the programme on parents' perceptions of social support

- The process evaluation highlighted the need for social contact with other parents

- The generalisability of the findings is limited by the small sample size

\section{Keywords}

Group parenting programme; parenting; randomised controlled trial; parental self-efficacy. 


\section{Introduction}

\subsection{Background}

There is a substantial body of evidence to indicate that parenting programmes are effective in improving outcomes for both parents and children. Parenting programmes can help to improve: parent responsiveness; parent child interactions and parenting confidence (Barlow, Smailagic, Huband, Roloff \& Bennett, 2014). They have been shown to contribute to a reduction in negative parenting practices, parent anxiety and depression (Barlow, Coren, \& Stewart-Brown, 2003; Barlow, Smailagic, Bennett, Huband, Jones, \& Coren, 2011; Furlong, McGilloway, Bywater, Hutchings, Smith, Donnelly \& O’Neill, 2012) as well as positively impact on the emotional and behavioural adjustment of children (Barlow, Smailagic, Ferriter, Bennett, \& Jones, 2010; Barlow \& Parsons, 2005). Over the past decade there has been a new sense of urgency around the importance of promoting healthy family and parenting practices. This is reflected in current UK and Northern Irish government agendas which acknowledge the vital role of parenting in aiding children to be emotionally, socially, behaviorally and physically healthy into adulthood (Allen, 2011; Department of Education, 2010; Marmot, 2010). Consequently, there has been a surge of new initiatives and parenting programmes, many of which are aimed at parents of children from birth to five, in recognition that the early years of a child's life are the most important for shaping their future (Barlow et al., 2010; Fonagy, 1998; Bandura, 1969; Bowlby, 1988).

Parenting programmes are delivered in a variety of formats, some are universal but many are aimed at specific groups of children or parents who are likely to be more vulnerable, for example families living in socioeconomically deprived areas (Belsky, Melhuish, Barnes, Leyland, Romaniuk \& the National Sure Start Research Team, 2006), children who are at risk of developing conduct disorders (Leijten, Raaijmakers, de Castro, van den Ban, \& Matthys, 2015) or teenage mothers (e.g. Olds, 2006). 
Programmes can also be delivered in a variety of contexts such as in the family home, delivered during home visits by a nurse or family visitor (e.g. the Nurse Family Partnership; Olds, 2006) or in a group setting for example in a school, community or clinic (e.g. Surestart; Belsky et al., 2006). Programmes frequently utilise standardized manuals or curriculums, booklets and handout materials, as well as discussion, role-play and video modelling techniques.

In response to the growing number of parenting programmes available, a considerable evidence-base regarding their effectiveness has also built up. Consequently, a number of systematic reviews - aimed at summarising this research - have been carried out (Barlow et al., 2014; Barlow et al., 2010; Barlow \& Underdown, 2005; Barlow \& Parsons, 2005; Thomas, Camiletti, Cava, Feldman, Underwood \& Wade, 1999) providing convincing evidence that parenting programmes are an effective way of improving both parent and child outcomes. Fostering a strong, good quality parent-child relationship in the very early years - based on a secure attachment relationship (Fonagy, 1998; Bowlby, 1988) - is key to the healthy social, emotional and behavioural development of the child, and to the child forming secure relationships later in life (Barlow et al., 2010; Barlow \& Parsons, 2005; Warren, Huston, Egeland \& Sroufe, 1997). Thus, parenting programmes which directly support the parent-child relationship in the early years can be particularly effective in promoting improved child outcomes (Barlow et al, 2010; Barlow, Parsons \& Stewart-Brown, 2005; Barlow \& Parsons, 2005; Regalado \& Halfon, 2001). Similarly, many programmes aim to improve and support parental psychosocial health (for example, depression, stress, anxiety and confidence), which in turn impacts on child outcomes through improving the parentchild relationship and the effectiveness of parenting (Miller et al., 2011; Barlow et al., 2003; Kaminski, Valle, Filene \& Boyle, 2008). 


\subsection{Parental self-efficacy}

A range of theoretical frameworks are commonly used as the underpinning for parenting programmes. These include; behavioural, cognitive-behavioural, attachment theory and family systems. The theoretical framework a particular programme adopts is influenced by the outcomes it aims to address for parents and children, and this in turn often influences the techniques used to deliver the programme. An important part of being a 'good parent' is how you think about yourself as a parent and this cognitive appraisal can have a measurable impact on parenting behaviour (Coleman \& Karraker, 1998). As such, many researchers have drawn on Bandura's $(1977,1982)$ self-efficacy theory to better understand this cognitive dimension of parenting (see for example, Cutrona \& Troutman, 1986; Teti \& Gelfand, 1991; Coleman \& Karraker, 1998, 2000, 2003; Jones \& Prinz 2005).

Self-efficacy relates to an individual's perception and expectation of how well they think they will cope in a given situation. It influences how much effort a person will expend and how long they will persevere with a task when challenges get in the way (Bandura 1977, 1982). Individuals with high self-efficacy tend to be persistent, not blame themselves for failure and report lower stress and anxiety than those with low self-efficacy (ibid). Self-efficacy beliefs specific to the parenting role are referred to as parenting (or parental) self-efficacy (PSE) (Cutrona and Troutman, 1986). Parental self-efficacy relates to a parent's belief that they can be a competent, effective parent (Teti and Gelfand, 1991) and positively influence the development of their child (Coleman and Karraker, 1998). Independent of other variables, maternal self-efficacy is directly related to maternal behaviour and can mediate and explain the association normally observed between the behavioural competence of the mother and other known psychosocial correlates of parenting quality such as economic background, infant temperament, social support and depression (Teti and Gelfand 1991). 
The process through which self-efficacy beliefs affect parenting competence and quality of care is through affective, motivational, cognitive and behavioural pathways (Coleman \& Karraker, 1998). High parental self-efficacy is correlated with competent parenting behaviour and positive parenting practices (Jones \& Prinz, 2005; Machida, Taylor \& Kim, 2002) and is known to play an important role in parents' psychological functioning. It is inversely related to both maternal depression (Cutrona \& Troutman, 1986; Teti \& Gelfand, 1991) and parental stress (Gross, Fogg \& Tucker, 2005; Scheel \& Rieckmann, 1998) and there is further evidence that it is positively associated with role satisfaction (Coleman \& Karraker, 2000) and influenced by the parents' personal characteristics (Sevigny \& Loutzenhiser, 2009). The direction of these associations remains relatively unclear however and the specific role of parental selfefficacy as an antecedent, consequence or transactional variable has still to be established (Jones \& Prinz, 2005). Parental self-efficacy can also positively impact on child behaviour (Bohlin \& Hagekull, 2009; Day, Factor \& Szkibaday, 1994; Bogenschneider, Small \& Tsay, 1997; Coleman \& Karraker, 2003), social-emotional functioning (Murry \& Brody, 1999) and school achievement (Bogenschneider et al., 1997; Ardelt \& Eccles, 2001) - both directly and indirectly through parenting behaviour, parental adjustment and parental involvement. Of course, self-efficacy isn't the only correlate of parenting competency; other maternal factors are also involved, including: personality, stress and depression, knowledge of child development, attitudes and beliefs about parenting, desires and expectations (Coleman \& Karraker, 1998). However, given the evidence summarised above which indicates a direct and indirect effect of parental self-efficacy on both parent and child outcomes, improving parental selfefficacy through intervention is a valid approach to improving a range of outcomes for both parents and children. 


\subsection{Description of the DELTA Parenting Programme}

The DELTA Parenting Programme is a universal, group-based programme whose mission is 'to promote partnership with parents and carers on a multi-disciplinary basis through group and individual programmes by imparting parenting information and advice'. The programme is usually delivered in the school setting and is divided into five age ranges, from birth to 16 years. The focus of the current evaluation is the Early Years (EYS) strand of the programme, which is aimed specifically at parents of pre-school children and comprises six weekly meetings. Each group consists of approximately 14 parents and meetings last between one and two hours with tea and coffee provided. The meetings are parent focused and are orientated around six themes:

1. Promoting learning and thinking skills

2. Health and routines

3. Language and literacy skills

4. Learning through play

5. Maths all around us, and

6. Positive parenting and managing behaviour

The DELTA programme aims to provide parents with information appropriate to the developmental stage of their child through short talks, demonstrations and written booklets. In addition, the programme provides and encourages a relaxed social context through which parents can meet and engage with each other and the group facilitator. It is this provision of practical information and advice, in an informal supportive context that is thought to increase parents' confidence in their parental role and enhance their support networks. 
It is clear from the research literature that parenting quality is essential for the development of positive child outcomes (e.g. Gross et al., 2005). The Early Years DELTA programme aims to improve the quality of parenting by providing developmentally relevant information, modelling appropriate behaviours and techniques, and providing support and advice (through the group facilitator as well as peer support via other attending parents). This combination of information and support is thought to lead to an increase in parents' confidence in their parenting ability, specifically parental self-efficacy which is an important factor in achieving behavioural change. Thus, an improvement in parental self-efficacy might be one of the first steps towards some of the more behavioural changes described above such as healthy life choices, increased activities with the child, using positive parenting styles and using appropriate behaviour management techniques. This can be broadly thought of as a simple logic model, which depicts how the programme might work, namely, that the activities that make up the programme result in changes in parents' feelings of efficacy and confidence as well as their perceived social experiences.

\subsection{Aim of the current evaluation}

It is with the above in mind that the current study, conducted between September 2012 and June 2013, sought to provide an impact evaluation to determine, in a methodologically rigorous way, whether the Early Years DELTA programme improves the parental self-efficacy (primary outcome) and social experiences (secondary outcome) of parents who take part compared to those who do not.

The study aimed to answer the following research questions:

1. Does the Early Years DELTA Parenting programme improve parental self-efficacy for those parents who take part in the programme? 
2. Does the Early Years DELTA Parenting programme improve parenting perceived support for those parents who take part in the programme?

3. What is the experience of parents who take part in the programme?

\section{Methodology}

To address the research questions, the evaluation consisted of two elements:

1. A cluster randomised controlled trial $(\mathrm{RCT})$ to evaluate the effectiveness of the DELTA parenting programme in improving parent outcomes.

2. A qualitative process evaluation, which was conducted alongside the RCT and explored parent (and child) outcomes in more depth as well as the process of programme delivery.

This combined approach to evaluation provides a robust method of determining whether a programme works whilst also exploring other important questions related to outcomes and process (Oakley, Strange, Bonell, Allen, Stephenson, 2006). An RCT provides a reliable and valid means of detecting measurable improvement in parent outcomes (compared to a no-intervention control group) over the period of the intervention and can effectively answer the important question 'does this programme work?'. There are however other key questions that need to be addressed for us to better understand how a programme works and how it might be improved. For this reason, conducting a process evaluation alongside a trial allows us to explore whether the proposed theory of change is valid as well as whether there are issues related to programme implementation or fidelity.

The evaluation was part funded by the DELTA organisation and this raises a potential conflict of interest, which could undermine the independence of the research team. Whilst bias cannot ever be completely 
eliminated, the following steps were employed to maximise objectivity: a robust RCT methodology was employed and the trial's management was overseen by the Centre for Effective Education. Furthermore, the internal validity of the trial was strong such that schools were randomly allocated to condition using computer software, valid and reliable outcome measures were used and the CONSORT guidelines have been adhered to in reporting the trial to ensure transparency. The study received ethical approval from the School of Education Research Ethics Committee, Queen's University Belfast.

The RCT methodology and results are reported first of all, followed by a report of the process evaluation and its findings. The findings from both elements of the evaluation are then summarised and discussed in the concluding section of the paper.

\subsection{RCT Design}

The early years DELTA parenting programme is delivered through participating schools, thus a cluster randomised controlled trial design was used to evaluate the impact of the programme where the unit of randomisation was the school. Each school had an equal chance of being allocated to either the intervention or control group.

\subsection{RCT Sample}

Sample size. Previous evaluations of group parenting interventions have reported effect sizes in the region of 0.34 (Barlow et al., 2014) in favour of the intervention group. Sample size calculations were conducted using Optimal Design, version 3.01 and based on a two-level cluster design. Using the following assumptions it was estimated that the current trial would have $80 \%$ power to detect an effect size of Hedges' $g=0.37$ : 
- $\quad$ Significance level $(\alpha)=0.05$

- Number of parents per school $=14$

- $\quad$ Number of schools $=23$

- Estimated intraclass correlation coefficient $(\rho)=0.04$

- Per cent of explained variation by Level 2 covariate $\left(R^{2}\right)=0.5$

School recruitment and allocation. Primary and nursery schools in the Southern Education and Library Board area of Northern Ireland were approached by DELTA and asked if they would like to take part in the evaluation. Interested schools/nurseries (settings) were sent written information about the study by the research team who followed this up with telephone contact. Twenty-three settings provided written consent to take part in the study, prior to being randomly allocated to either the intervention or control group. The research team allocated schools to intervention and a 'wait-list' control using Stata version 12.1 and informed schools directly of their allocation.

Schools allocated to the intervention group $(n=12)$ delivered the DELTA programme to parents for six weeks in October/November 2012. Schools allocated to the wait-list control group $(n=11)$ did not deliver the programme during the period of the evaluation but instead conducted 'business as usual'. The control group did not receive any alternative or placebo condition however they were put on a waiting list to receive the DELTA programme the following school term in spring 2013. This enabled the integrity of the allocation to be preserved whilst allowing the control group to avail of the programme at the end of the evaluation if they so wished. 
Parent recruitment and consent. Parents were eligible to take part in the study if their child's school was participating in the study and their child was in either nursery, pre-school or P1 (i.e. aged between three and five years). In September 2012 the research team sent all eligible parents (via the school) written information about the evaluation, inviting them to take part. To minimise the research burden on the parents, this initial pack of information also contained the pre-test questionnaire and consenting parents returned the completed questionnaire to the research team in a Freepost envelope provided. Approximately 1500 parents across all 23 participating schools were invited to take part in the study. Due to the nature of the intervention it was not possible to blind either schools or parents to their allocation.

\subsection{RCT Data collection}

Participating parents in both the intervention and control groups completed the outcome measures at two time points:

1. Pre-test: at the start of the RCT in September/October 2012 (before the intervention group started the programme)

2. Post-test: six to eight weeks later, when parents in the intervention group had finished the programme

The pre-test questionnaires were sent to parents through the school along with detailed information about the study and consent forms outlining what was involved for parents who chose to participate. A Freepost envelope was included to return the completed questionnaire and consent form. At this juncture parents were also asked for their address information so that the research team could mail the 
post-test questionnaires to them directly without having to send them through the schools. The questionnaire took approximately 30 minutes to complete.

\subsection{RCT Outcomes and Measures}

Based on the pathway by which the programme is thought to work, two key outcomes were identified: parental self-efficacy and social support (with parental self-efficacy identified as the primary outcome). The Tool to Measure Parenting Self Efficacy (TOPSE) (Kendall, 1991) was used to measure parental selfefficacy and is a widely used, valid and reliable measure of this outcome. It consists of eight domains (see Table 1), many of which are specifically relevant to the aims of the DELTA Parenting Programme. For each domain parents are presented with a series of six statements and are asked to indicate on a scale from zero to ten how much they agree or disagree with each statement. Examples of statements that are contained in this measure include: I am and confident that my child can come to me if they are unhappy; I can plan activities that my child will enjoy, and; I can get my child to behave well without a battle. For each of the eight domains an average rating, which could vary between zero and ten, was calculated with a low score indicating low efficacy in that domain and a high score indicating high efficacy.

Social support was measured using the Social Experiences Checklist (Oostrom, Tijhuis, de Haes, Tempelaar \& Kromhaut, 1995). This is a 16 -item scale that requires respondents to draw on their social experiences with other people over the past month. Eight of the 16 items relate to positive social experiences and eight to negative experiences. Respondents are asked to indicate the frequency with which they have experienced (over the last month) different reactions, for example: warmth and friendliness; that someone avoided them, and; that someone took time to be with them. An overall 
mean score of all 16 items was calculated for this outcome, which ranged between one (indicating a very poor social experience) and four (indicating a very good social experience).

Table 1: Outcomes and measures used in the RCT

\begin{tabular}{|c|c|c|}
\hline Outcomes & Measures & $\begin{array}{l}\text { Reliability within the } \\
\text { current study } \\
\text { (Cronbach's alpha) }\end{array}$ \\
\hline Parenting self-efficacy & $\begin{array}{l}\text { Tool to Measure Parenting Self-Efficacy } \\
\text { (TOPSE) (Kendall, 1991). The TOPSE } \\
\text { consists of } 48 \text { self-efficacy statements } \\
\text { that address eight domains of parenting: } \\
\text { 1. Emotion and affection } \\
\text { 2. Play and enjoyment } \\
\text { 3. Empathy and understanding } \\
\text { 4. Control } \\
\text { 5. Discipline and boundary setting } \\
\text { 6. Pressures of parenting } \\
\text { 7. Self-acceptance } \\
\text { 8. Learning and knowledge }\end{array}$ & $0.62-0.91$ \\
\hline Social support & $\begin{array}{l}\text { The Social Experiences Checklist } \\
\text { (Oostrom et al., 1995). This measure } \\
\text { assesses social experiences (based on } \\
\text { experiences in the last month) with eight } \\
\text { items measuring positive experiences } \\
\text { and eight items measuring negative } \\
\text { experiences. }\end{array}$ & $0.77-0.84$ \\
\hline
\end{tabular}

The measures were fully piloted prior to use to ensure suitability and identify any issues arising related to administration such as timing, and ease of comprehension. In addition, background and demographic information were collected from parents including: age, gender, highest level of education, occupation and number of children in the family. 


\section{Randomised controlled trial results}

\subsection{Sample characteristics}

In total 334 parents (22\%) completed a pre-test questionnaire, 231 were in the intervention group and 103 were in the control group. At post-test 125 parents (37\%) returned a post-test questionnaire: 76 were in the intervention group and 45 were in the control group (see Figure 1).

Figure 1: Flow diagram of school allocation and testing

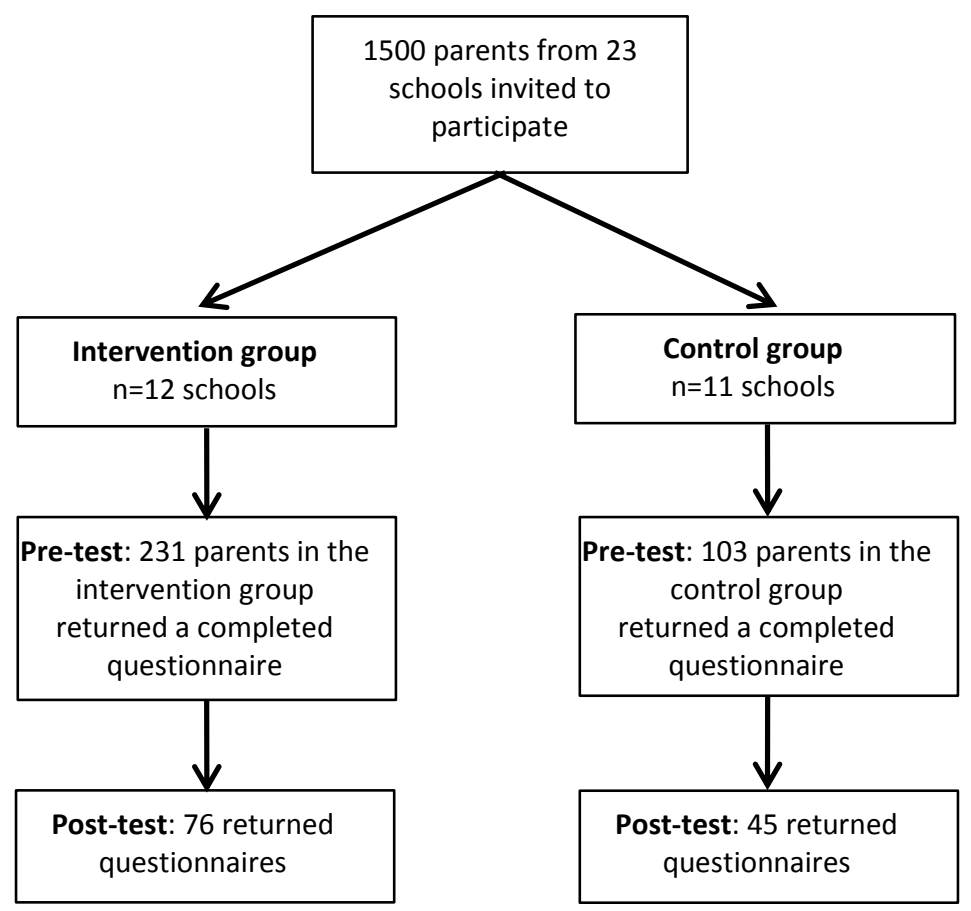

Overall, $93 \%$ of the respondents were mothers or a female legal guardian and $7 \%$ were fathers. On average respondents had 2.5 children. Thirty seven per cent $(37 \%)$ of mothers and $27 \%$ of fathers in the sample had a university level education. Fifty eight per cent (58\%) of the mothers were in work and $35 \%$ were looking after the home and family. Over $90 \%$ of fathers were working. 
The initial characteristics of the intervention and control groups were compared at pre-test in relation to their core characteristics and mean scores on the main outcomes. There were no differences between the intervention and control groups in relation to family size (Chi square=6.96, $d f=5, p=0.22$ ), level of maternal (Chi square $=9.92, d f=6, p=0.13$ ) or paternal (Chi square $=5.59, d f=6, p=0.47$ ) education or the employment status of the father (Chi square $=4,28, d f=4, p=0.37$ ). The exception to this was the employment status of the mother where slightly more mothers in the intervention group $(n=13)$ reported being unemployed compared to the control group $(n=0)$ (Chi square $=13.11, d f=6, p=0.04$ ). Those parents who attended the programme reported attending an average of 4.9 (out of a possible six) sessions overall.

There were no pre-test differences between the intervention and control groups on any outcomes except the Learning and Knowledge subscale of the TOPSE which was rated higher for the intervention group (see Table 2). Pre-test differences in means were calculated using regression models with robust standard errors with the outcome as the dependent variable and group allocation as the independent variable. Pre-test scores were also used as a covariate in the main analysis to control for any pre-test differences however, the lack of statistically significant differences between intervention and control groups for all other outcomes suggests that the randomisation process worked in producing two equivalent groups. 
Table 2: Intervention and control group differences in outcomes at pre-test

\begin{tabular}{|c|c|c|c|c|}
\hline \multicolumn{5}{|c|}{ Pre-test mean score (SD) } \\
\hline Outcome & $\begin{array}{l}\text { Intervention } \\
\text { Group }\end{array}$ & $\begin{array}{l}\text { Control } \\
\text { Group }\end{array}$ & Min, max values & Significance \\
\hline $\begin{array}{l}\text { Total Parental Self- } \\
\text { efficacy (TOPSE) }\end{array}$ & $\begin{array}{l}8.67 \\
(0.05)\end{array}$ & $\begin{array}{c}8.59 \\
(0.09)\end{array}$ & 0,10 & $p=0.30$ \\
\hline $\begin{array}{r}\text { TOPSE Learning and } \\
\text { Knowledge }\end{array}$ & $\begin{array}{c}8.86 \\
(1.10)\end{array}$ & $\begin{array}{c}8.48 \\
(1.30)\end{array}$ & 0,10 & $p<0.01$ \\
\hline TOPSE Self Acceptance & $\begin{array}{c}8.87 \\
(1.08)\end{array}$ & $\begin{array}{c}8.80 \\
(0.99)\end{array}$ & 0,10 & $p=0.52$ \\
\hline $\begin{array}{r}\text { TOPSE Discipline and } \\
\text { Boundary Setting }\end{array}$ & $\begin{array}{c}7.88 \\
(1.44)\end{array}$ & $\begin{array}{c}7.84 \\
(1.40)\end{array}$ & 0,10 & $p=0.68$ \\
\hline $\begin{array}{r}\text { TOPSE Emotion and } \\
\text { Affection }\end{array}$ & $\begin{array}{c}9.46 \\
(0.63)\end{array}$ & $\begin{array}{c}9.46 \\
(0.70)\end{array}$ & 0,10 & $p=0.99$ \\
\hline $\begin{array}{r}\text { TOPSE Play and } \\
\text { Enjoyment }\end{array}$ & $\begin{array}{c}9.31 \\
(0.84)\end{array}$ & $\begin{array}{c}9.19 \\
(0.95)\end{array}$ & 0,10 & $p=0.44$ \\
\hline $\begin{array}{r}\text { TOPSE Empathy and } \\
\text { Understanding }\end{array}$ & $\begin{array}{c}8.92 \\
(0.91)\end{array}$ & $\begin{array}{c}8.78 \\
(1.01)\end{array}$ & 0,10 & $p=0.18$ \\
\hline TOPSE Control & $\begin{array}{c}7.69 \\
(1.23)\end{array}$ & $\begin{array}{c}7.77 \\
(1.42)\end{array}$ & 0,10 & $p=0.51$ \\
\hline TOPSE Pressures & $\begin{array}{c}7.36 \\
(1.77)\end{array}$ & $\begin{array}{c}7.56 \\
(1.74)\end{array}$ & 0,10 & $p=0.11$ \\
\hline Social experiences & $\begin{array}{c}3.16 \\
(0.35)\end{array}$ & $\begin{array}{c}3.17 \\
(0.31)\end{array}$ & 1,4 & $p=0.89$ \\
\hline
\end{tabular}


It emerged that parents who completed questionnaires at pre- and post-test $(n=115)$ were more likely to have a higher level of education - both mothers (Chi square $=28.62, d f=6, p<0.01$ ) and fathers (Chi square $=22.28, d f=6, p<0.01$ ) - than those who did not return a post-test questionnaire. There were no other demographic differences between those who did and did not return the post-test questionnaires.

\subsection{Main analysis}

Data were analysed using Stata version 12.1 (Stata Corporation, College Station, Texas, USA) and all continuous variables were standardised prior to analysis (with a mean of zero and standard deviation of 1). The main analysis took into account the hierarchical nature of the data since parents (unit of analysis) were nested within group settings (unit of randomisation and cluster variable). The effects of the intervention were estimated using a clustered sandwich estimator (Williams, 2000), to allow for the fact that observations within clusters cannot be considered to be independent. Failing to account for this hierarchical structure within the data risks biased standard error estimates and inflates the Type I Error rate. This can result in spurious statistical significance and an erroneous rejection of the null hypothesis i.e. concluding that there are between group differences, when in fact none exist (Donner, 1998). To test how similar to each other individuals within a cluster are, the intraclass coefficient (ICC) can be calculated. A high ICC suggests that individuals within clusters are very similar to each other and not independent, meaning that the risk of biased standard error estimates (and subsequently biased $\mathrm{p}$ values in favour of statistical significance) is also high. The ICCs for each outcome in the current study were found to be very low - between zero and 0.04 - indicating that despite the nested nature of the data, the individual responses of parents within clusters were relatively independent of each other. 
A series of models were estimated for each outcome measure. For each model, the relevant outcome measure at post-test formed the dependent variable and a number of independent variables were added including: group allocation and parents' pre-test scores for the outcome variable in question. The main focus for the analysis was the estimated coefficient associated with the dummy variable that represented the difference in mean scores on the respective outcome variable between the intervention and control groups. This coefficient was then used to estimate the effect size of the programme in relation to the respective outcome variable as the standardised mean difference between the two groups (Hedges' g)

After controlling for pre-test scores, the mean scores on each outcome at post-test (as soon as the programme was completed) are reported in Table 3. While the intervention group generally scores higher on every outcome there was no effect of the intervention on overall parental self-efficacy (as measured by the total TOPSE score), or social experiences.

Closer inspection of the subscales of the TOPSE however, reveals a more nuanced picture and it can be seen that there are statistically significant differences between groups at this level. Specifically, parents in the intervention group (and compared to the control group) are reporting improved efficacy with respect to Learning and Knowledge (Hedges' $g=0.43, p=0.01$ ), Self-Acceptance (Hedges' $g=0.38, p=0.02$ ) and Discipline and Boundary Setting (Hedges' $g=0.25, p=0.01$ ). These changes suggest that the DELTA parenting programme is effective in producing small but measurable improvements in parents' parental self-efficacy, specifically in relation to three of the outcome areas measured, namely parents' confidence in: their knowledge of their child's development and needs; their self-acceptance as a good parent, and; disciplining and setting boundaries for their child. 
Table 3: Summary of main effects at post-test

\begin{tabular}{|c|c|c|c|c|}
\hline \multirow[b]{2}{*}{ Outcome } & \multicolumn{3}{|c|}{ Adjusted post-test mean (SD) } & \multirow[b]{2}{*}{ Significance } \\
\hline & $\begin{array}{c}\text { Intervention } \\
\text { Group }\end{array}$ & $\begin{array}{l}\text { Control } \\
\text { Group }\end{array}$ & $\begin{array}{c}\text { Effect size } \\
\text { (Hedges' g) } \\
(95 \% \mathrm{Cl})\end{array}$ & \\
\hline Total Parental Self- & 0.12 & -0.03 & 0.15 & $p=0.12$ \\
\hline efficacy (TOPSE) & $(0.90)$ & $(1.13)$ & $(-0.03,0.34)$ & \\
\hline Learning and & 0.21 & -0.20 & 0.43 & $p=0.01$ \\
\hline Knowledge & $(0.85)$ & (1.08) & $(0.16,0.71)$ & \\
\hline \multirow[t]{2}{*}{ Self Acceptance } & 0.22 & -0.15 & 0.37 & $p=0.02$ \\
\hline & $(0.85)$ & $(1.17)$ & $(0.09,0.64)$ & \\
\hline Discipline and & 0.10 & -0.15 & 0.25 & $p=0.01$ \\
\hline Boundary Setting & $(0.91)$ & $(1.11)$ & $(0.08,0.41)$ & \\
\hline \multirow[t]{2}{*}{ Emotion and Affection } & 0.08 & -0.01 & 0.08 & $p=0.39$ \\
\hline & $(0.95)$ & $(1.08)$ & $(-0.10,0.27)$ & \\
\hline \multirow[t]{2}{*}{ Play and Enjoyment } & 0.04 & 0.01 & 0.03 & $p=0.84$ \\
\hline & $(0.97)$ & $(1.04)$ & $(-0.22,0.27)$ & \\
\hline Empathy and & 0.08 & 0.01 & 0.07 & $p=0.57$ \\
\hline Understanding & $(0.98)$ & $(1.03)$ & $(-0.17,0.32)$ & \\
\hline \multirow[t]{2}{*}{ Control } & 0.01 & -0.02 & 0.02 & $p=0.81$ \\
\hline & $(0.96)$ & $(1.07)$ & $(-0.16,0.21)$ & \\
\hline \multirow[t]{2}{*}{ Pressures } & -0.05 & 0.06 & -0.10 & $p=0.30$ \\
\hline & $(1.07)$ & $(0.89)$ & $(-0.29,0.08)$ & \\
\hline \multirow[t]{2}{*}{ Social experiences } & -0.17 & -0.24 & 0.07 & $p=0.45$ \\
\hline & (1.03) & $(0.96)$ & $(-0.11,0.24)$ & \\
\hline
\end{tabular}




\section{Process evaluation methodology}

\subsection{Design}

A process evaluation was conducted alongside the RCT in order to provide more in-depth data on both the outcomes and implementation of the Early Years DELTA Parenting Programme. The interviews were conducted by the research team and took place once post-test data collection for the RCT was complete. Specifically, the following research questions were addressed and explored from the perspective of parents who had taken part in the RCT:

- What is the experience of parents who take part in the programme?

- Do the experiences of parents in the intervention group reflect the theory of change and outcomes hypothesised by the logic model

- What is the overall parental satisfaction with the Early Years DELTA Parenting Programme

- What are the perceived benefits (or otherwise) of participation in the Early Years DELTA Parenting Programme

Process evaluations such as this one are an important, integral and complementary part of RCTs of complex social interventions (Oakley et al., 2006). They have the potential to enable evidence-based knowledge to be combined with, and understood in the light of, theory-based and experience-based knowledge (Audrey, Holliday, Parry-Langdon, \& Campbell, 2006). Such evaluations are recommended because they provide a valuable alternative view that isn't otherwise provided by the RCT and can help to disentangle and better understand the complexity of effects often reported by evaluations of social or educational interventions (Craig, Dieppe, Macintyre, Michie, Nazareth, \& Petticrew, 2008). 


\subsection{Sample}

When completing the questionnaire for the RCT data collection parents were asked if they would like to also take part in an interview about their experience of the programme. A random selection of eleven parents - who agreed and provided contact information - were invited to also take part in this element of the evaluation. In the following section the findings from these interviews are presented through discussion of the areas described above. Where participants are quoted, their words have been taken directly from interview transcripts.

\subsection{Approach to analysis}

Interviews and focus groups were transcribed and analysed using the framework approach. This analytical technique is particularly suitable and useful for applied mixed methods research where qualitative and quantitative findings are linked. It is deductive rather than inductive as it is led by the existing aims of the research and thus a priori in nature. For this reason the data collection is more structured than other more inductive analytical approaches.

\section{Process evaluation findings}

\subsection{Sample characteristics and reasons for taking part in DELTA}

Of the 11 parents who took part in the interviews, nine of them had two children or more, all of whom were primary school age or younger. In terms of the number of DELTA programme sessions attended by parents, the majority of parents attended all six of the sessions, with two parents attending only two sessions out the possible six due to sickness and a lack of childcare cover. In response to being asked why they chose to participate in the DELTA programme, the majority of parents interviewed said that they took part in order to find out more information about what their child is learning in school and to 
pick up 'tips' on how to help with their child's learning at home, as well as to find out more about parenting skills.

\subsection{Perceived benefits of the DELTA programme.}

Interviewees were asked about their overall impression of the DELTA programme, what they liked most and what they viewed as the main benefit to them of attending the course. All respondents were positive when asked about their overall impression of the DELTA programme. Their responses ranged from them finding the course to be 'very informative', giving great advice and tips on different ways of learning, to being 'very sociable'. When asked about which aspect of the DELTA programme they liked the most, parents responded with two main answers, both of which related to enhancing their knowledge of their child's development. The first of these was that many parents found the Maths (numeracy) session to be the aspect of the course that they liked the most. Parents liked learning through playing the numeracy games during the session and it gave them good ideas for using with their children at home. Secondly parents responded that gaining 'insight into new ways of dealing with things', being provided with information about how their child learns and being given tips and advice was what they enjoyed most about attending the programme:

Interviewees were then asked about what they viewed as the main benefit to them of attending the DELTA programme. Similar to the previous question, parents stated that the main benefit was in 'learning something new', receiving advice and finding out about different ways of helping their children. They also indicated that the group dimension of the programme was important and that meeting other parents was a 'good social thing', which enabled them to share 'little tips about 
behaviour'. It was generally felt that the programme reassured them in their role as a parent and gave them 'a bit more confidence' that they're 'actually not doing a bad job'.

In addition to valuing the information and resources that the course provided, parents also valued the role of the DELTA promoter and considered their advice to be a trustworthy source of reassurance: 'so to hear that, you know, it's normal, that what my child was doing is exactly what children should do.' All of the interviewees responded positively in relation to the facilitators and reported that they found them 'excellent', very helpful and easy to talk to.

Parents were also asked what they liked least about the programme and whether they would change or improve any aspects of the programme. For the most part parents reported that they had enjoyed the whole programme and wouldn't change anything. A small minority of the respondents stated that they 'didn't get as much' from the session on nutrition and healthy lifestyles and it was the aspect of the programme that they liked the least because 'most of us already knew what she was going to say before she said it'. Similarly, a small number of respondents said that they thought there could have been more sessions included in the course, relating specifically to positive parenting, phonics and extending what they had already learned during the session on numeracy.

\subsection{Changes in parenting}

At the conclusion of the interviews, parents were asked about how they felt their own parenting and children had changed since taking part in the DELTA programme. With regard to changes in parenting since taking part, there was a clear response from the majority of parents interviewed. Parents noted that they had become more aware of their children's development and tried to parent more positively. 
They reported doing 'a lot more with them at home', 'taking time out to listen' to their children more and spend more time reading with them.

Finally, parents were asked whether they had noticed any changes in their children since taking part in the DELTA programme. Parents responded in two main ways. Either they said they hadn't noticed a change (some stating they thought it was 'too soon' to notice anything), while others said they noticed that there was 'less stress' in the home, with parents feeling better equipped to deal with their child' behaviour as well as there being a better understanding between parent and child.

\subsection{Summary.}

It is clear that the parents who were interviewed thought very highly of the DELTA programme and the promoters, deriving a great deal of enjoyment and benefit from attending. The main benefits included learning new information about their child's development and needs in a practical and 'hands on' way, as well as the opportunity to meet other parents. Many parents mentioned that consequently they set aside more time for their children, involved themselves more in their play and tried to see the world from their point of view. This seemed to lead to parents reporting greater confidence in their parenting skills and less tension at home as certain behaviours ceased to be viewed as the battleground they once were. These experiences and reflections very much support the hypothesised logic model and the outcomes that were chosen as the primary focus of the RCT i.e. parenting confidence and social contact with other parents. Parents reported a high level of satisfaction with the programme and the majority of parents felt that no element of it needed to be changed. Some parents suggested that in fact extending the programme to go into more depth on issues, particularly around positive parenting and numeracy, would be helpful. 


\section{Discussion}

6.1 Parental self-efficacy

Overall this evaluation has shown that parental self-efficacy improved as a result of taking part in the DELTA programme. Whilst the positive change in total parental self-efficacy did not achieve statistical significance in this sample, a positive effect of $g=0.15$ cannot be disregarded and a difference of this magnitude in a larger sample might well have achieved statistical significance. Nevertheless, certain specific domains of parental self-efficacy did show statistically significant improvement, namely parents' confidence in: their knowledge of their child's development and needs; their self-acceptance as a good parent, and; disciplining and setting boundaries for their child. These three domains of parenting confidence very much reflect the main focus of the DELTA programme which is to provide developmentally appropriate knowledge and information about a child's learning and development this was the outcome which showed the largest improvement (Knowledge and Learning); reassure parents that they are doing a good job (Self-Acceptance), and; model positive parenting techniques using appropriate behaviour management strategies (Discipline and Boundary Setting). The trial provided no evidence of measurable change in the remaining five domains of parental efficacy; Emotion and Affection, Play and Enjoyment, Empathy and Understanding, Control, and Pressures.

This study adds to the evidence (e.g. Ulfsdotter, Enebrink, \& Lindberg, 2014; Shorey, Chan, Chong \& He, 2015; Barlow et al., 2003) that parental self-efficacy can be improved through intervention and the positive changes in confidence observed in the intervention group in this study are commensurate with evaluations of other programmes similar in focus and duration. Indeed, a meta-analysis of the impact of group parenting programmes on parental confidence (which included 16 studies) has shown that on average such programmes can increase parents' confidence in the parenting role achieving effect sizes 
in the region of $\mathrm{ES}=0.34(95 \% \mathrm{Cl}: 0.17,0.51)$ (Barlow et al., 2003) and is consistent with the findings from the current RCT.

However, confidence in the parenting role on its own isn't a sufficient condition for mastery in a situation (Bandura 1977). In order for parents to feel efficacious they also need to be equipped with the necessary knowledge so that they know the appropriate action to take in a given parenting situation, they need to feel confident in their ability to take that action and they need to believe that their child will respond accordingly (Coleman and Karraker, 1997). In response to some reports of a null association between parental self-efficacy and parenting competence (Conrad et al., 1992; Leerkes \& Crockenberg, 2002) a study by Hess, Teti and Hussey-Gardner (2004) explored the independent and the mediating role of knowledge of child development between self-efficacy and parenting competence in mothers of medically at risk infants. Whilst they found no direct relation between either knowledge of child development or parental self-efficacy and parent behaviour, they did find that knowledge of child development interacted with self-efficacy to predict maternal competence in play interactions, such that better knowledge and high parental self-efficacy predicted more competent behaviour. Although this interaction was statistically significant it accounted for only a small proportion of the overall variance in parenting behaviour (5-9\%), nevertheless, this study highlights the need for programmes to aim to improve knowledge of child development as well as parental self-efficacy. The results from the current trial also reflect the importance of parenting knowledge and it was this domain of parental selfefficacy (knowledge of child development and needs) that improved the most for parents who attended the DELTA programme, followed closely by an improvement in their acceptance of being a good parent. 
According to Bandura $(1977,1982)$ self-efficacy beliefs can arise from four sources: 1$)$ personal experience and history of success and failures, 2) learning vicariously through watching other people, 3) verbal persuasion i.e. listening to other people's feedback about your potential to accomplish a task, and 4) emotional arousal such that a an individual is more likely to anticipate failure if they are experiencing a negative or stressful state of arousal. Thus, parenting programmes (e.g. Shorey et al., 2015) offer a valuable opportunity to influence parents' self-efficacy beliefs through both vicarious learning and verbal persuasion (Cutrona \& Troutman, 1986). Within this environment, parents are able to observe the programme facilitators model appropriate parenting behaviours in addition to being exposed to verbal support and encouragement from facilitators - and other parents - which can further help to shape parents' beliefs about their ability to be a good parent.

\subsection{Parents' social experiences}

Although no changes were observed in the social experiences measure this was identified through participant interviews as an important feature of the programme. It should also be noted that the social experiences of parents at pre-test were already very high with a mean pre-test score of 3.16 out of a maximum score of 4 , thus detectable positive movement on this particular outcome might have been more difficult to realise. Interestingly, in the meta analysis mentioned above, all of the included programmes emphasised the importance of the 'social component' of their programme however no evaluation of any of these studies measured the programme's impact on social support or social experiences, thus it is not possible to estimate how this outcome changes for parents who attend such programmes. Whilst not measured in the current evaluation other studies have clearly shown that programmes like DELTA can positively impact on other related parental outcomes including, among 
other outcomes, depression, anxiety, stress and partner satisfaction (e.g. Gardner, Burton \& Klimes, 2006; Gallart \& Matthey, 2005; Fantuzzo, Stevenson, Abdul Kabir \& Perry, 2007; Greaves, 1997).

\subsection{Limitations}

It should be noted that the sample size of this trial was relatively small and that the final achieved sample was only a sub cohort of those who originally completed a pre-test questionnaire. Although only three of the ten outcomes measured showed evidence of positive change it is important to note that a larger trial with greater power might be able to detect more subtle differences between groups in the future. Moreover, only a small proportion $(22 \%, n=334)$ of all the parents invited to take part $(n \sim 1500)$ agreed to do so and it is possible that these parents differed in some way from those parents who did not consent to take part. Although we cannot make any assertions about the how characteristics of the parents who did take part compared to those who did not, there is some evidence that parents who have high self-efficacy are more likely to make an effort to improve their parenting by attending parenting classes and reading appropriate literature and materials (Spoth \& Conroy 1993). Nevertheless, if this were the case and more efficacious parents took part in the current study, it is noteworthy that the programme still made a measurable difference to their parental self-efficacy - boding well for parents who might have low parental self-efficacy and could potentially benefit even more from the programme. Thus, whilst these results are the reality for this particular sample of parents, we cannot be sure that they are representative of the impact of the programme might have on the wider population of parents. 


\subsection{Recommendations}

This study and the literature reviewed confirm that both parenting knowledge and efficacy need to be targeted by parenting programmes. Improving parental self-efficacy in the absence of also improving knowledge and skills risks what Hess et al. (2004) refer to as 'naïve confidence' whereby mothers with high parental self-efficacy but poor knowledge of child development are less competent than mothers with low parental self-efficacy (ibid). Further research is needed to better understand the precise nature of the role that parental self-efficacy plays in improving parent and child outcomes as well as to better understand whether such improvements are sustained over time. Little is known about the long-term impact of such interventions and, similar to other evaluations of parenting programmes, this evaluation lacked a follow-up component so it is not possible to know whether the effects of the intervention were maintained or not. With this in mind, future research evaluating parenting programmes should be sufficiently powered and include a follow up period if we are to understand whether (and for how long) parent and child benefits are maintained beyond immediate post-test.

\subsection{Conclusions}

DELTA is a strengths-based programme, which aims to improve the quality of parenting through the provision of information, support, advice and the development of positive parenting techniques and skills. This small but robust evaluation has shown that taking part in this group based parenting programme results in improvement in three areas of parental self-efficacy: knowledge of children's development and needs; self-acceptance as a good parent, and; discipline and boundary setting. Parents' experience of the programme and the group facilitators was very positive and interviews with those had received the programme provided a more in-depth look at how the programme works for parents who take part. Overall, the findings from this evaluation are very encouraging and consistent 
with other robust evaluations of similar programmes. DELTA is a short-term programme lasting only six weeks. Thus being able to measurably improve parental self-efficacy in this short period of time has the potential to be an effective and cost-effective means to improving a range of parent and child outcomes upstream.

\section{Acknowledgements}

This study was funded by the DELTA Parenting Partnership Service, the Southern Education and library Board (SELB) and the Southern Health and Social Care Trust (SHSCT). 


\section{References}

Allen, G. (2011). Early Intervention: The next steps. An independent report to Her Majesty's Government. HM Government, Cabinet Office, London. United Kingdom.

Ardelt, M., \& Eccles, J.S. (2001). Effects of mothers' parental efficacy beliefs and promotive parenting strategies on inner-city youth. Journal of Family Issues, 22(8), 944-972.

Audrey, S., Holliday, J., Parry-Langdon, N., Campbell, R. (2006). Meeting the challenges of implementing process evaluation within randomized controlled trials: the example of ASSIST ( A Stop Smoking in Schools Trial). Health Education Research, 21(3), 366-377.

Bandura, A. (1969). Principles of Behavior Modification. New York: Holt, Rinehart \& Winston.

Bandura, A. (1977). Self-efficacy: Toward a unifying theory of behavioural change. Psychological Review, 84, 191-215.

Bandura, A. (1982). Self-efficacy in human agency. American Psychologist, 37, 122-147.

Barlow, J., Coren, E., \& Stewart-Brown, S. (2003). Parent-training programmes for improving maternal psychosocial health. Cochrane Database of Systematic Reviews, 4(Art. No.:CD002020). DOI: 10.1002/14651858.CD002020.pub2.

Barlow, J., \& Parsons, J. (2005). Group-based parent-training programmes for improving emotional and behavioural adjustment in 0-3 year old children. Campbell Systematic Reviews 2005.2 DOI: $10.4073 /$ csr.2005.2 
Barlow, J., Parsons, J., \& Stewart-Brown, S. (2005). Preventing emotional and behavioural problems: the effectiveness of parenting programmes with children less than 3 years of age. Child: Care, Health \& Development, 31,1,33-42.

Barlow, J., Smailagic, N., Bennett, C., Huband, N., Jones, H., \& Coren, E. (2011). Individual and group based parenting programmes for improving psychosocial outcomes for teenage parents and their children. Cochrane Database of Systematic Reviews, 3(Art. No.: CD002964). DOI: 10.1002/14651858.CD002964.pub2.

Barlow, J., Smailagic, N., Ferriter, M., Bennett, C., \& Jones, H. (2010). Group-based parenttraining programmes for improving emotional and behavioural adjustment in children from birth to three years old. Cochrane Database of Systematic Reviews, 3(Art. No.: CD003680). DOI: 10.1002/14651858.CD003680.pub2.

Barlow, J., Smailagic, N., Huband, N., Roloff, V., \& Bennett C. (2014). Group-based parent training programmes for improving parental psychosocial health. Cochrane Database of Systematic Reviews, 5(Art. No.: CD002020). DOI: 10.1002/14651858.CD002020.pub4.

Barlow, J., \& Underdown, A. (2005). Promoting the social and emotional health of children: where to now? The Journal of the Royal Society for the Promotion of Health, 125(2), 64-70. DOI: $10.1177 / 146642400512500209$.

Belsky, J., Melhuish, E., Barnes, J., Leyland, A.H., Romaniuk, H., \& the National Evaluation of Sure Start Research Team. (2006). Effects of Sure Start local programmes on children and families: early findings from a quasi-experimental, cross sectional study. BMJ, DOI:

10.1136/bmj.38853.451748.2F 
Bogenschneider, K., Small, S.A., \& Tsay, J.C. (1997). Child, parent and contextual influences on perceived parenting competence among parents of adolescents. Journal of Marriage and the Family, 59(2), 345-362.

Bohlin, G., \& Hagekull, B. (2009). Socio-emotional development: from infancy to young adulthood. Scandinavian Journal of Psychology, 50(6), 592-601.

Bowlby, J. (1988). Clinical Applications of Attachment Theory. London: Routledge.

Coleman, P.K., \& Karraker, K.H. (1998). Self-efficacy and parenting quality: findings and future applications. Developmental Review, 18(1), 47-85.

Coleman, P.K., \& Karraker, K.H. (2000). Parenting self-efficacy among mothers of school-age children: conceptualization, measurement and correlates. Family Relations, 49(1), 13-24.

Coleman, P.K., \& Karraker, K.H. (2003). Maternal self-efficacy beliefs, competence in parenting and toddlers' behavioral and developmental status. Infant Mental Health Journal, 24(2), 126148.

Conrad, B., Gross, D., Fogg, L., \& Ruchala, P. (1992). Maternal confidence, knowledge and quality of mother toddler interactions - a preliminary study. Infant Mental Health journal, 13(4), 353-362.

Craig, P., Dieppe, P., Macintyre, S., Michie, S., Nazareth, I., \& Petticrew, M. (2008). Developing and evaluating complex interventions. British Medical Journal, 337, a1655. 
Cutrona, C.E., \& Troutman, B.R. (1986). Social support, infant temperament and parenting selfefficacy - a meditational model of postpartum depression. Child Development, 57(6), 15071518.

Day, D.M., Factor, D.C., \& Szkibaday, P.J. (1994). Relations among discipline style, childbehavior problems and perceived ineffectiveness as a caregiver among parents with conduct problem children. Canadian Journal of Behavioural Science, 26(4), 520-533.

Department of Education. (2010). Early Years (0-6) Strategy. London. United Kingdom: Department of Education.

Donner, A, (1998). Some aspects of the design and analysis if cluster randomization trials. Journal of the Royal Statistical Society. Series C (Applied Statistics), 47(1), 95-113.

Fantuzzo, J., Stevenson, H., Abdul Kabir, S., Perry, M.A. (2007). An investigation of a community-based Intervention for socially isolated parents with a history of child maltreatment. Journal of Family Violence, 22, 81-9. [MEDLINE: 36550; : 0885-7482]

Fonagy, P. (1998). Prevention, the appropriate target of infant psychotherapy. Infant Mental Health Journal, 19(2), 124-150.

Furlong, M., McGilloway, S., Bywater, T., Hutchings, J., Donnelly, M., Smith, S., \& O’Neill, C. (2012). Behavioural and Cognitive-Behavioural Group-Based Parenting Programmes for EarlyOnset Conduct Problems in Children Aged 3 to 12 Years. The Campbell Library, 8, 12(Art. No.: CD008225). DOI: 10.1002/14651858.CD008225.pub2.

Gallart, S.C., \& Matthey, S. (2005). The effectiveness of group Triple P and the impact of the four telephone contacts. Behaviour Change, 22(2), 71-80. [MEDLINE: 940; : CN-00569669] 
Gardner, F., Burton. J., \& Klimes, I. (2006). Randomised controlled trial of a parenting intervention in the voluntary sector for reducing child conduct problems: outcomes and mechanisms of change. Journal of Child Psychology and Psychiatry, and Allied Disciplines, 47(11), 1123-32. [MEDLINE: 410; : CN-00573306]

Gross, D., Fogg, L. \& Tucker, S. (2005). The efficacy of parent training for promoting positive parent-toddler relationships. Child: Care, Health \& Development, 31, 25-32.

Greaves D. (1997).The effect of rational-emotive parent education on the stress of mothers of children with Down Syndrome. Journal of Rational-Emotive and Cognitive-Behavior Therapy, 15(4), 249-67.

Hess, C.R., Teti, D.M., Hussey-Gardner, B. (2004). Self-efficacy and parenting of high-risk infants: the moderating role of parent knowledge of infant development. Applied Developmental Psychology, 25(4), 423-437.

Jones, T.L., \& Prinz, R.J. (2005). Potential roles of parental self-efficacy in parent and child adjustment: a review. Clinical Psychology Review, 25(3), 341-363.

Kaminski, J.W., Valle, L.A., Filene, J.H., \& Boyle, C.L. (2008). A meta-analytic review of components associated with parent training program effectiveness. Journal of Abnormal Child Psychology, 36, 567-589. DOI: 10.1007/s10802-007-9201-9.

Kendall, S. (1991). A home visit by a health visitor using Bandura's theory of self-efficacy. In While, A. (Ed.) Caring for children: Towards partnership with families. London: Arnold. 
Leerkes, E.M., \& Crockenberg, S.C. (2002). The development of maternal self-effciacy and its impact on maternal behavior. Infancy, 3(2), 227-247.

Leijten, P., Raaijmakers, M.A.J., Orobio, B., van den Ban., \& Matthys, W. (2015). Effectiveness of Incredible Years Parenting Program for families with socioeconomically disadvantaged and ethnic minority backgrounds. Journal of Clinical Child and Adolescent Psychology, DOI:

$10.1080 / 15374416.2015 .1038823$

Machida, S., Taylor, A.R., \& Kim, J. (2002). The role of maternal beliefs in predicting home learning activities in Head Start families. Family Relations, 51, 176-184.

Marmot, M., Allen, J., Goldblatt, P., Boyce, T., McNeish, D., Grady, M., \& Geddes, I. (2010). Fair Society, Healthy Lives. The Marmot Review. London, United Kingdom: Strategic Review of Health Inequalities in England Post-2010.

Miller, S., Maguire, L.K., \& Macdonald, G. (2011) Home-based child development interventions for preschool children from socially disadvantaged families. Cochrane Database of Systematic Reviews, 12(Art. No.: CD008131). DOI: 10.1002/14651858.CD008131.pub2.

Murry, V.M., \& Brody, G.H. (1999). Self-regulation and self-worth of black children reared in economically stressed, rural, single mother-headed families - The contribution of risk and protective factors. Journal of Family Issues, 20(4), 458-484.

Oakley, A., Strange, V., Bonell, C., Allen, E., \& Stephenson, J. (2006). Process evaluation in randomised controlled trials of complex interventions. British Medical Journal, 332, 413. doi: http://dx.doi.org/10.1136/bmj.332.7538.413 
Olds, D. L. (2006). The nurse-family partnership: An evidence-based preventive intervention. Infant mental Health Journal, 27(1), 5-25.

Oostrom, M.A., Tijhuis, M.A.R., de Haes, J.C.J.M., Tempelaar, R. \& Kromhout, D. (1995). A measurement of social support in epidemiological research: the social experiences checklist tested in a general population in The Netherlands. Journal of Epidemiology and Community Health, 49, 518-524.

Regalado, M., \& Halfon, N. (2001). Primary care services promoting optimal child development from birth to age 3 years. Archives of Pediatrics \& Adolescent Medicine, 155(12), 1311-1322. DOI: 10.1001/archpedi.155.12.1311.

Scheel, M.J., \& Rieckmann, T. (1998). An empirically derived description of self-efficacy and empowerment for parents of children identified as psychologically disordered. American Journal of Family Therapy, 26(1), 15-27.

Sevigny, P.R., \& Loutzenhiser, L. (2010). Predictors of parenting self-efficacy in mothers and fathers of toddlers. Child Care Health and Development, 36(2), 179-189.

Shorey, S., Chan, S.W.C., Chong, Y.S., \& He, H.G. (2015), A randomized controlled trial of the effectiveness of a postnatal psychoeducation programme on self-efficacy, social support and postnatal depression among primiparas. Journal of Advanced Nursing, 71(6), 1260-1273.

Spoth, R. L., \& Conroy, S. M. (1993). Survey of Prevention-Relevant Beliefs and Efforts to Enhance Parenting Skills Among Rural Parents. The Journal of Rural Health, 9, 227-239.

Teti, D.M., \& Gelfancd, D.M. (1991). Beahvioral competence among mothers of infants in the $1^{\text {st }}$ year - the meditational role of maternal self-efficacy. Child Development, 62(5), 918-929. 
Thomas, H., Camiletti, Y., Cava, M., Feldman, R., Underwood, J., \& Wade, K. (1999).

Effectiveness of parenting groups with professional involvement in improving parent and child outcomes. Ontario Ministry of Health, Region of Hamiliton-Wentworth, Social and Public Health Services Division.

Ulfsdotter, M., Enebrink, P., \& Lindberg, L. (2014). Effectiveness of a universal healthpromoting parenting program: a randomized waitlist-controlled trial of All Children Focus. BMC Public Health, 14, 1083.

Warren, S. L., Huston, L., Egeland, B., \& Sroufe, L. (1997). Child and adolescent anxiety disorders and early attachment. Journal of the American Academy of Child \& Adolescent Psychiatry, 36(5), 637-644.

Williams, R. L. 2000. A note on robust variance estimation for cluster-correlated data. Biometrics 56, 645-646. 